\title{
Tourism Cultural and Creative Product Design for Guye Shell Mound Archaeological Site based on SIPS Model
}

\author{
Cai Pei ${ }^{1}$ \\ ${ }^{1}$ Guangzhou Vocational and Technical University of Science and Technology, Guangzhou, China
}

\begin{abstract}
This paper aims to explore the applications of SIPS idea in tourism cultural and creative product design for Guye shell mound archaeological site. Through combining the internet investigation with field investigation and from the angle of sympathy, identification, participation, share and spread of consumer behavior pattern, the position of tourism cultural and creative product design in Guye shell mound archaeological site are analyzed as well as combining the design with practice, an innovative way with a higher enjoyment, readability, emotion of tourism cultural and creative product design in archaeological sites is explored.
\end{abstract}

\section{Introduction}

With the strengthening of economic globalization and the acceleration of modernization, tourism development has been an effective way to scientifically and rationally inherit and utilize the culture of archaeological sites. Tourism cultural and creative product has become a link that shall be improved fast. ${ }^{[1]}$ As the subject of tourism activities, tourists' recognition and consumption towards tourism cultural and creative products are the crucial factors for the sustainable development of cultural and creative products in archaeological site culture. Based on SIPS model analysis of modern consumption behavior, this paper conducts an innovative design for tourism cultural and creative product in Guye shell mound archaeological site.

\section{Charming of Archaeological Elements in Guye Shell Mound Archaeological Site}

Guye shell mound archaeological site is the most complete, typical, scientific, meticulous and important sites among lots of discovered shell mounds in Lingnan region at present, ${ }^{[2]}$ and it represents a new type of archaeological culture. It was awarded one of naonal top ten archaeological discoveries by the Chinese Academy of Social Sciences in 2006, officially incorporated into the national cultural relics within the twelfth five- year plan library in 2011 as well as approved and announced as one of the seventh batch of national key cultural relics protection units by the State Council on March 5th, 2013, (see Guo Fa [2013] no. 13 document for details). (See Table 1).
Table 1 charming of ancient elements in Guye shell mound archaeological site

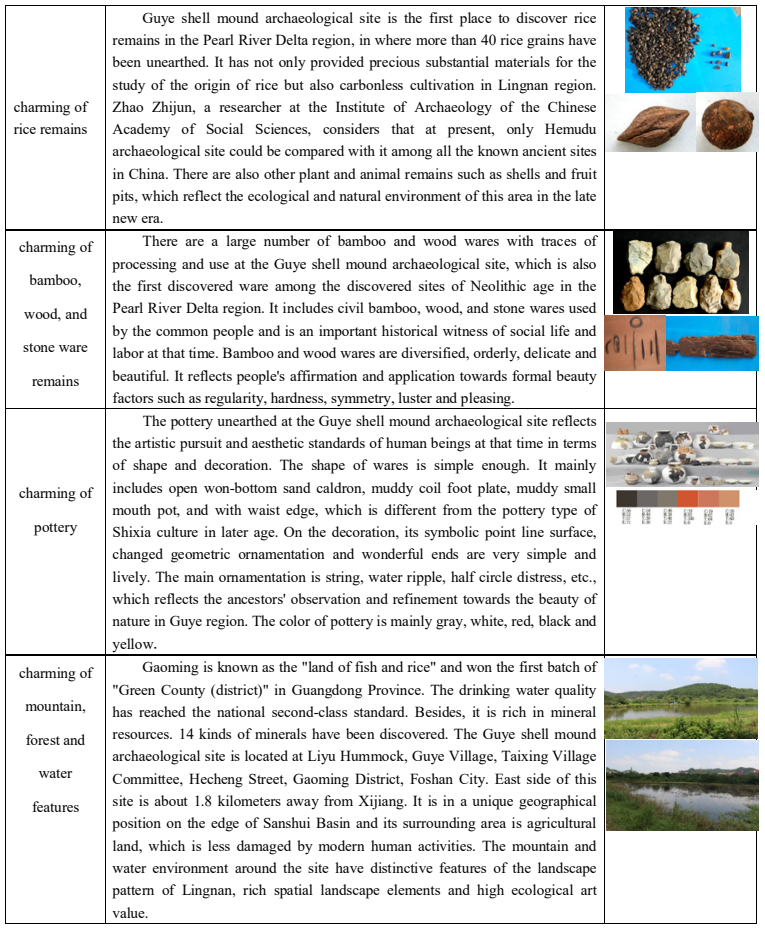

\section{Excavation and Extraction of Archaeological Elements}

Excavating obvious cultural characteristics contained in abundant archaeological elements of tourism resources at the Guye shell mound archaeological site in late new age (see Table 2), trying to make the abstract cultural perceived, understandable, participatory and can be studied, ${ }^{[3]}$ and organically integrating them with modern 
culture and tourism product design, can develop an fresh inspiration, which is not only advantageous to the reproduction and transmission of cultural values of the sites but also enable to help visitors get the spiritual satisfaction.

Table 2 cultural information of Guye shell mound archaeological site

\begin{tabular}{|c|c|c|}
\hline element & feature extraction & design element \\
\hline sculpt & $\begin{array}{l}\text { orderly, simple, } \\
\text { lively and practical }\end{array}$ & 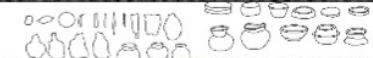 \\
\hline color & $\begin{array}{l}\text { nature, gray, white, red, } \\
\text { black and ycllow. }\end{array}$ & \\
\hline pattern & $\begin{array}{l}\text { symbolic point line } \\
\text { surface, vein, string, } \\
\text { water ripple, half circlc, } \\
\text { and radial distress }\end{array}$ & $\underset{0}{0} \mathbb{a}$ \\
\hline landscape & $\begin{array}{l}\text { exploration, paddy fields, } \\
\text { reservoirs, wetlands, soft } \\
\text { paths, border forests }\end{array}$ & \\
\hline
\end{tabular}

\section{Consumer Behavior Analysis of Tourism Cultural and Creative Product at Archaeological Sites}

The research data analysis of consumer behavior is the most important field in the design and dissemination of tourism cultural and creative products in Guye shell mound archaeological site. ${ }^{[4]}$ In order to obtain consumer real data through the questionnaire and interview form as well as analyze and summary the effective 378 pieces of questionnaires from July 2019 to June 2020. This paper designs survey questionnaire based on the SIPS idea and takes the consumers who have visited the Guye shell mound archaeological site relics exhibition and internet tourism cultural and creative product as the main survey crowd. The new features showed by consumer behavior in the era of internet digital sites cultural tourism could be summarized as follows.

\subsection{Polarization Trend of Consumption Crowed of Tourism Form and Product at Archaeological Sites}

According to the survey data, the driving force of cultural tourism consumption behavior and tourism demand of Guye shell mound archaeological site are based on science education and parent-child travel, accounting for $81.25 \%$, and the elderly group accounts for $45.31 \%$. At the same time, archaeological site tourism appears to the trend of extension at both ends of young age and old age (see Figure 1). The total number of respondents in this survey is 378 , among whom more than 50\% are teenagers aged 18-25 (see Figure 2), indicating that teenagers pay more attention and participation to the research of tourism cultural and creative products related consumption.

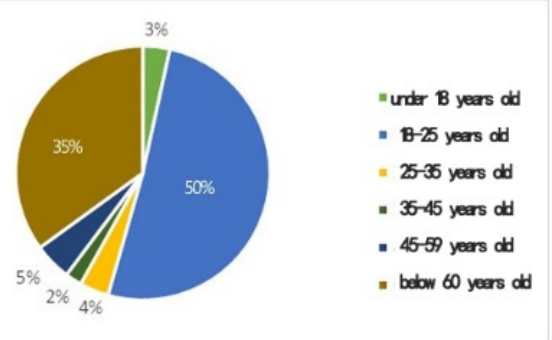

Figure1. age distribution of sites tourism

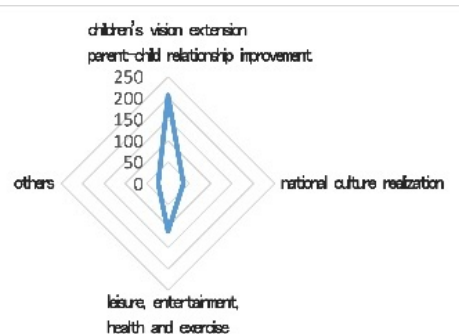

Figure 2. motivation of sites tourism

\subsection{Low Acceptance Price Towards Consumption Product}

In terms of the purchase price of tourism cultural and creative products, most respondents indicate that they could accept the price range within 100-300 yuan, and about $33 \%$ of them choose the price range within 100 yuan (see Figure 3), which means that most people who participate in the tourism of ancient sites have low acceptance towards the expensive cultural and creative products.

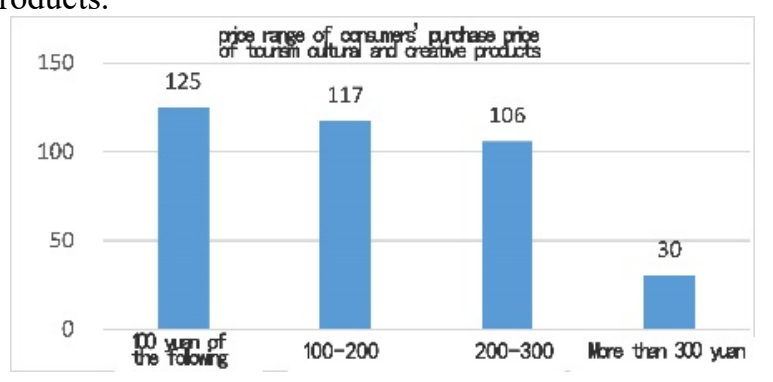

Figure 3. price range of consumers' purchase price of tourism cultural and creative products

\subsection{Internet Becomes the Main Way to Purchase Tourism Cultural and Creative Product}

According to the data of the survey questionnaire "consumer purchase way", $85 \%$ of consumers choose the Internet, and consumers' consumption behavior tends to be more casual (see Figure 4). According to the in-depth interview, we know that due to mobile devices such as mobile phones and tablets without time and space restrictions, online consumption can be carried out anytime and anywhere during travel. 


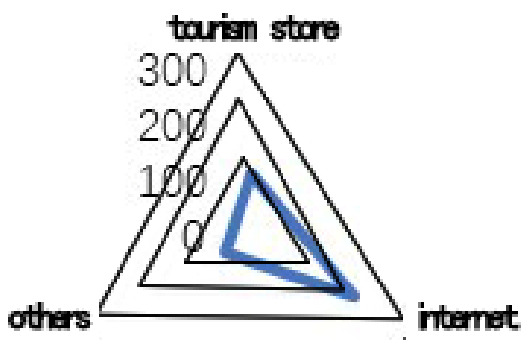

Figure 4. consumers' purchase way

\subsection{Focusing on Personalized and Interesting Product Design Demand}

According to the survey data, consumers' behavior towards tourism cultural and creative product tend to personalized products and are wilder to the sculpt style, creative pattern or practical value of tourism cultural and creative products, which makes the tourism cultural and creative products purchased by consumers have more personalized characteristics (see Figure 5).

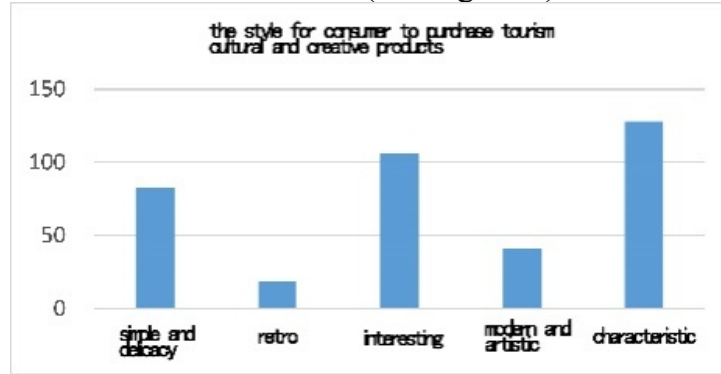

Figure 5.the style for consumer to purchase tourism cultural and creative products

\subsection{Focusing on Product with a sense of Participation Demand}

According to the survey data, most people are more willing to choose tourism cultural and creative products with practical life and a sense of participation (see Figure 6). In-depth interviews show that tourism cultural and creative products have a single form and lack of new consumption highlights, which makes it difficult to stimulate consumers' consumption enthusiasm. In order to further develop tourism cultural and creative products, attention must be paid to the terms of participation in design, ${ }^{[5]}$ which not only makes tourists feel impulsive and happy when buying tourism cultural and creative products, but also includes lasting appreciation and education functions as well as leaves tourists an unforgettable tourism memory and enable them feel kind and nostalgia when use tourism cultural products. ${ }^{[6]}$

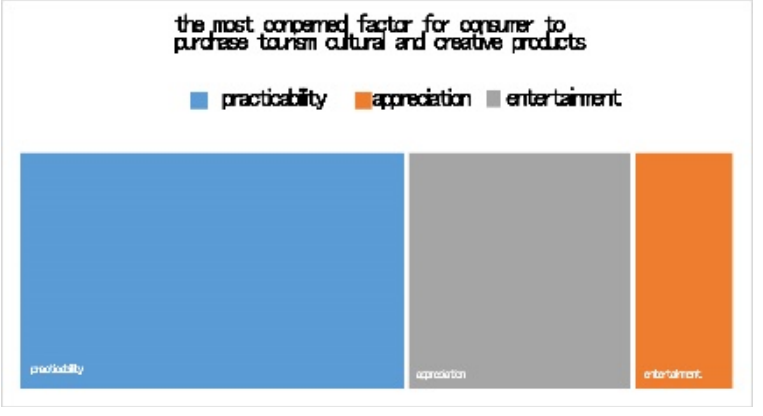

Figure 6.the most concerned factor for consumer to purchase tourism cultural and creative products

\section{Creative Design Case}

Excavating the cultural connotation of Guye shell mound archaeological site deeply, the design, color, sculpt and other elements could be visually extracted and the characteristics of consumers' sympathy, identification, participation, share and spread could be easily analyzed. And, through case design and application, tourism cultural and creative products in line with consumer behavior could be designed. Summarizing and extracting the characteristic elements of Guye shell mound archaeological site culture and adding modern design techniques to simply reflect the cultural connotation of the ancient site could play a more convenient spread effect. ${ }^{[1]}$ Tourism cultural and creative product design model of Guye shell mound archaeological site based on the SIPS idea is shown as follow (see Figure 7).

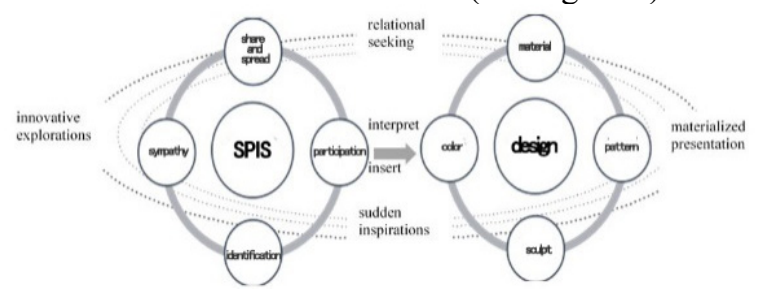

Figure 7. Tourism cultural and creative product design model of Guye shell mound archaeological site based on the SIPS idea

\subsection{Brand Logo Design of Tourism Cultural and Creative Products}

According to the above idea, the brand logo of tourism cultural and creative products could be designed, it includes that through line, selecting the shell and rice in element of Guye shell mound archaeological site and reconstructing a new edition with ancient character in Guye shell mound archaeological site as well as integrating them enable to form a new logo and for its font, the archaic-looking of stone ware and the gold color of pottery are taken as its main color, which stands for the connotation of oriental culture and the development trend of the times. 


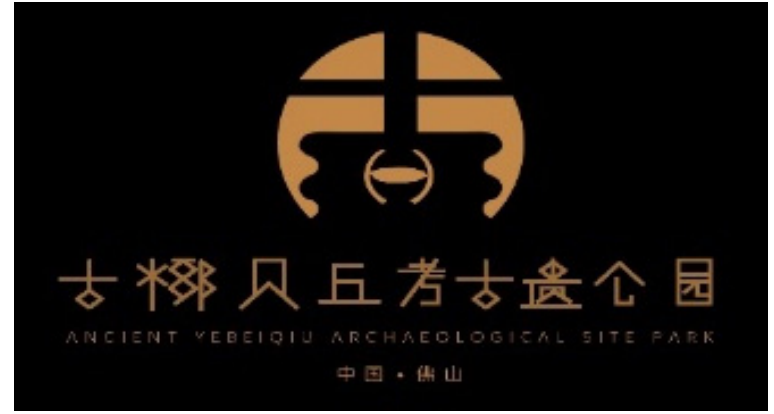

Figure 8. brand logo design of Guye shell mound archaeological site

\subsection{Brand Logo Design of Tourism Cultural and Creative Product for Guye Shell Mound Archaeological Site}

Based on the above research, the design framework of tourism cultural and creative products for Guye shell mound archaeological site is put forward. Combing cultural elements with product creativity to form a new cultural and creative product, is more in line with the market demand of consumers. ${ }^{[2]}$ Based on consumers' daily consumption customs, this design provides consumers with the spread experience of ancient sites culture. Design of multi-functional Guye magnetic fragrance lamp is shown as follow (See Figure 9).

The combination design of a set of toiletries is shown as follow (see Figure 10), the primitive and simple stone shape in the Guye shell mound archaeological site culture is selected for the outer shape to deep process as well as the modern composition design method and aesthetic taste are applied. At the same time, the elements are gradually extracted through the selection and change to show both the outside shape and inner meaning ${ }^{[3]}$.
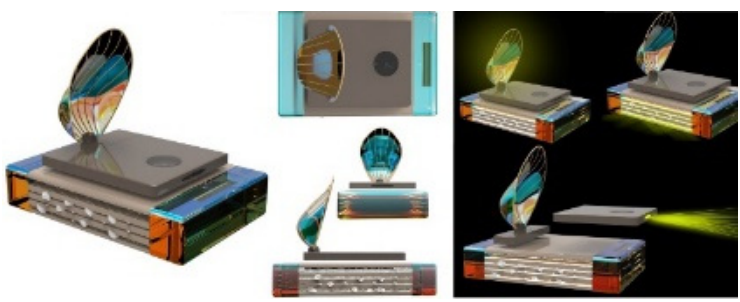

Figure9 Design of multi-functional Guye magnetic fragrance Lamp

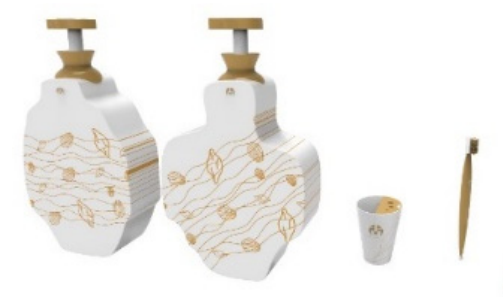

Figure10 combination design of a set of toiletries

\section{Conclusion}

The creative core of cultural and creative products is the inheritance and innovation of national culture. ${ }^{[4]}$ Tourism cultural and creative products, as a commodity, not only need to have unique cultural connotation, but also start from the modern consumer behavior pattern to close contact with consumers in daily life, which makes tourism cultural and creative products truly enter the consumer market. From the view of SPIS consumption pattern and tourism product design research for Guye shell mound archaeological site, this paper concludes that practical and cultural influence on consumers' purchasing behavior is bigger. In addition, introducing it into the actual design case is an efficient way to improve the development of tourism cultural and creative products as well as help archaeological sites culture become easily heritage and protect.

\section{Acknowledgement}

Fund project: one of achievements of the Youth Innovative Talents Fund Project of Guangdong Province Department of Education (project number:2018WQNCX234)

\section{References:}

1. Darren J- Timothy, Stephen W- Boyd. Heritage tourism [M]. Translated by Cheng Jinneng. Beijing: Tourism Education Press, 2007: 66.

2. "Protection and Planning of Guyebeiqiu Site 2018-2035". People's Government of Gaoming District, Foshan; Guangdong Provincial Institute of Cultural Relics and Archaeology, 2019

3. Written by Bob Mckercher, translated by Zhu Luping. Cultural Tourism and Cultural Heritage Management [M]. Tianjin: Nankai University Press, 2006

4. Han Yong. Study on Consumer Behavior in China from the Perspective of Behavioral Economics[J]. Market Modernization, 2014, 33: 16-18.

5. FengPeikui. Study on Tourism Product Development Planning Based on the New Generation Thought[D]. Xi'an: Xi' an University of Architectural Science and Technology.

6. MaGuangjun. Study on Sustainable Development of Site Tourism Development Project [J]. Business economy, 2009

7. Ao Jinghui. Teaching Practice of Cultural and Creative Products Design Course -- Taking Gift Design of Guangdong University of Finance and Economics as an example. [J]Decoration, 2017(2):136137

8. Yang Lei. Cultural and Creative Product Development of Classic Collection Reso urces at Museum -- Taking the Development of Zeng Houyi Chimes of Cultural and Creative Products as an example [J]. Southeast Culture,2018(1):122-126

9. Cui Yong. Creative Thinking in Art Design [M]. Beijing: Tsinghua University Press, 2013 
10. Piao Chengri. Research on the Development Strategy of Changbai Mountain Tourist Souvenirs. Hundred Schools of Art.2010(8):172-175 